\title{
Correspondence
}

\section{Why was the urine green?}

To the Editor:

We recently encountered an interesting problem in a routine case. A 55-yr-old previously healthy woman was scheduled for colpourethreopexy for stress incontinence. The only medications she was taking preoperatively were multivitamins, iron and Premarin. Preoperative elective urine and blood tests were normal. She was given lorazepam $2 \mathrm{mg} s l$ for sedation at bedtime. She was given an additional $10 \mathrm{mg}$ diazepam $p o$ one hour preoperatively because she was extremely anxious.

After arrival in the OR, anaesthesia was induced with propofol $2.5 \mathrm{mg} \cdot \mathrm{kg}^{-1}$ with $20 \mathrm{mg}$ lidocaine. She was given $100 \mathrm{mg}$ succinylcholine to facilitate tracheal intubation. Anaesthesia was maintained with $\mathrm{N}_{2} \mathrm{O}, \mathrm{O}_{2}$, sufentanil $0.5 \mu \mathrm{g} \cdot \mathrm{kg}^{-1}$ and isoflurane $0.4-0.5 \%$. After tracheal intubation, the bladder was catheterized and green urine was noted. This persisted for two hours following induction. Subsequently the surgeon filled the bladder with methylene blue solution. Her postoperative recovery was uneventful. The next day the patient denied noticing any abnormal urine colour before she came to hospital.

Propofol is known to cause green urine when used for prolonged intravenous infusion. ${ }^{1-5}$ We are not aware of any reports of an induction dose of propofol producing green urine. Although greenish discoloration is benign, it may be alarming for an anxious individual. It is even alarming to an anaesthetist as s/he may not be aware of all the causes or drugs inducing this condition. We are not aware of any other anaesthetic agent causing green urine. The antihistamine phenergan can also cause green urine. Other phenolic compounds have the propensity to produce green urine. In our patient there was no history of exposure to such compounds other than propofol.

For the sake of completion, we are including the following list of agents that may give rise to green urine. (-9 $^{-9}$ Owing to the presence of urochrome in urine, any blue compound in low concentrations may produce a green colour.

1 Phenol-containing compounds - iv cimetidine, iv promethazine (phenergan), $i v$ propofol.

2 OTC medicines - thymol, Listerine, magnesium salicylate (Doan's Pills), Dewitt's Pills, chlorophyll (Clorets).

3 Methylene blue - taken in proprietary pills or sweets.
4 Dyes such as indigo-blue, indigo-carmine, carbolic acid, flavine derivatives.

5 Bilverdin is an oxidation product of bilirubin and its presence in urine is usually seen in long-standing cases of obstructive jaundice.

6 Indican-A bacterial by-product of tryptophan. Indican urea is associated with stasis in GI tract and associated with malabsorption syndrome, bacterial overgrowth.

7 Amitriptyline.

8 Methocarbamol.

9 Resorcinol

10 Triamterene fluorescent green.

11 Iodochlor hydroxyquinine.

12 Pseudomonas infection due to pigments on the bacteria-pyocyanin, fluoroscein.

13 Hartnup's disease - a rare disease of trytophan transport.

14 Indomethacin (Indocid)

15 Phenyl butazone.

16 Azuresin (Diagnox).

17 Flutamide - a new drug used for prostate cancer.

We hope the above list will help the readers when confronted with green urine in the perioperative period.

Chidambaram Ananthanarayan MD FRCPC

Joseph A. Fisher MD FRCPC

Department of Anaesthesia

Mount Sinai Hospital

Toronto, Ontario

REFERENCES

1 Reeve WG, Wallace $P G M$. A survey of sedation in intensive care. Care of the Critically IIl 1991; 7: 238-41.

2 Weingarten $M$. Diprivan (propofol) for induction and maintenance of general anesthesia: experience from two clinical studies. Seminars in Anesthesia 1988; 7 Suppl 1: 85-90.

3 Kitson GE, Wauchob TD. Pulmonary oedema following carbamazepine overdose. Anaesthesia 1988; 43: 967-9.

4 Beller JP, Pottecher T, Lugnier A, Mangin P, Otteni JC. Prolonged sedation with propofol in ICU patients: recovery and blood concentration changes during periodic interruptions in infusion. Br J Anaesth 1988; 61: 583-8.

5 Hughes KR, Armstrong RF. Continuous infusion of propofol (Letter). Anaesthesia 1988; 483: 331.

6 Hart $F D(E d$.). French's Index of Differential Diagnosis, 12th ed. Bristol: Wright, 1985: 866. 
7 Cohen $M S$, Thill JR. What causes abnormally colored urine? Contemporary Urology 1993; 8: 13-9.

8 Schoepp GH. Ostomy care and incontinence. In: Carruthers-Czyzewski P (Ed.). Self-Medication: Reference for Health Professionals, Volume 1, 4th ed. Ottawa: Canadian Pharmaceutical Association, 1992: 389.

9 Robinson DC, Millares $M$. Renal diseases. In: Herfindal ET, Gourley DR, Hart LL (Eds.). Clinical Pharmacy and Therapeutics, 4th ed. Baltimore: Williams \& Wilkins, 1988: 208.

\section{The laryngeal mask airway - a consideration for the Neonatal Resuscitation Programme guidelines?}

To the Editor:

We read with interest Dr. Elliott's excellent introduction to the Neonatal Resuscitation Programme (NRP) guidelines. ${ }^{1}$ The design of sensible, practical algorithms and their widespread dissemination is an important step in improving neonatal outcome. Airway management options included in the guidelines, however, are confined to the facemask (FM) or tracheal tube (TT). Yet bagand-mask ventilation may be wholly ineffective ${ }^{2}$ and tracheal intubation may be impossible. Neonatal airway management may be difficult, even for those with advanced airway control skills. Furthermore $80 \%$ of neonates weighing $<1.5 \mathrm{~kg}$ require resuscitation ${ }^{3}$ and airway management may be technically more difficult. Advances in neonatal airway management are rare and interest is beginning to focus on the use of the laryngeal mask airway (LMA). ${ }^{4}$

The LMA offers several advantages over the FM during neonatal resuscitation. It avoids the necessity to form a seal on a slippery surface and manipulation of the head, neck and jaw is not required. It avoids pressure to the eyes and it may free the operator to perform other tasks such as CPR or administer drugs. The advantages over the TT include avoidance of laryngoscopy and its associated adverse effects, less invasion of the respiratory tract and avoidance of the risks of endobronchial or oesophageal intubation.

An attentuated haemodynamic stress resonse to LMA insertion is likely (although unproven in neonates) and this may be important in preventing intraventricular haemorrhage. Furthermore, placement is probably independent of factors governing facial and upper airway anatomy making the LMA particularly useful in the "cannot intubate, cannot ventilate" situation in neonates. Tra- cheal intubation may also cause laryngeal oedema and in the newborn $1 \mathrm{~mm}$ of oedema reduces the crosssectional area of the larynx by $65 \% .{ }^{5}$ Potential limitations of the LMA are that it may not be suitable for removal of meconium aspirate and may be inadequate for neonates who require high airway pressures - in these situations it is not a substitute for a TT.

A large proportion of neonatal resuscitation is performed by non-medical personnel ${ }^{6}$ who are infrequently exposed to advanced resuscitation techniques and may have difficulty in maintaining proficiency. ${ }^{7}$ Tests on neonatal intubation training models have shown that midwives and junior doctors can obtain a clear airway more rapidly with the LMA than the TT and with fewer failures, ${ }^{8}$ a similar finding to adults. ${ }^{9}$ In a prospective pilot study of neonates born with apnoea or heart rate $<110 \mathrm{~min}^{-1}$, experienced LMA users were able to resuscitate 20/20 neonates with the LMA at the first attempt. ${ }^{10}$ Our experience at Cairns Base Hospital is similar and extends to $39 / 40$ successful resuscitations (unpublished data). Three of these neonates weighed 1-1.5 kg." Denny et al. used an LMA to successfully resuscitate a $2.75 \mathrm{~kg}$ neonate with Pierre-Robin syndrome in whom intubation and facemask ventilation had failed. ${ }^{12}$ Whilst large-scale studies are required to evaluate the precise role of the LMA in neonatal resuscitation and to decide what level of initial and continued training is needed, these initial results and reports are encouraging.

\section{J. Brimacombe MB ChB FRCA}

A. Berry MB ChB FRCA

Dept Anaesthesia and Intensive Care

Cairns Base Hospital

The Esplanade

Cairns 4870

Australia

\section{REFERENCES}

1 Elliott RD. Neonatal resuscitation: the NRP guidelines. Can J Anaesth 1994; 41: 742-53.

2 Milner AD, Vyas H, Hopkin I. Efficacy of facemask resuscitation at birth. Br Med J 1984; 289: 1565-5.

3 Emergency Cardiac Care Committee and Subcommittees AH. Guidelines for cardiopulmonary resuscitation and emergency cardiac care: VII. Neonatal resuscitation. JAMA 1994; 268: 2276-81.

4 Robotham $J L$. Neonatal resuscitation using the laryngeal mask airway. Anesthesiology 1994; 80: $27 \mathrm{~A}$.

5 Holinger P, Johnston $K$. Factors responsible for laryngeal obstruction in infants. JAMA 1950; 143: 1229.

6 Standards and guidelines for cardiopulmonary resuscitation (CPR) and emergency cardiac care (ECC). Part VI. Neonatal advanced life support. JAMA 1986; 255: 2969-73. 